\title{
Beyond the Classic VTA: Extended Amygdala Projections to DA-Striatal Paths in the Primate
}

\author{
Julie L Fudge*,, ${ }^{*}$, Emily A Kelly', Ria Pal', Joseph L Bedont ${ }^{3}$, Lydia Park ${ }^{4}$ and Brian Ho ${ }^{5}$ \\ 'Department of Neuroscience, University of Rochester Medical Center, Rochester, NY, USA; '2Department of Psychiatry, University of Rochester \\ Medical Center, Rochester, NY, USA; ${ }^{3}$ Department of Neuroscience, University of Pennsylvania, Philadelphia, PA, USA; ${ }^{4}$ Jacobs School of \\ Medicine and Biomedical Sciences, State University of New York at Buffalo, Buffalo, NY, USA; ${ }^{5}$ Boston University School of Medicine, Boston, \\ MA, USA
}

\begin{abstract}
The central extended amygdala (CEA) has been conceptualized as a 'macrosystem' that regulates various stress-induced behaviors. Consistent with this, the CEA highly expresses corticotropin-releasing factor (CRF), an important modulator of stress responses. Stress alters goal-directed responses associated with striatal paths, including maladaptive responses such as drug seeking, social withdrawal, and compulsive behavior. CEA inputs to the midbrain dopamine (DA) system are positioned to influence striatal functions through mesolimbic DA-striatal pathways. However, the structure of this amygdala-CEA-DA neuron path to the striatum has been poorly characterized in primates. In primates, we combined neuronal tracer injections into various arms of the circuit through specific DA subpopulations to assess: (I) whether the circuit connecting amygdala, CEA, and DA cells follows CEA intrinsic organization, or a more direct topography involving bed nucleus vs central nucleus divisions; (2) CRF content of the CEA-DA path; and (3) striatal subregions specifically involved in CEA-DAstriatal loops. We found that the amygdala-CEA-DA path follows macrostructural subdivisions, with the majority of input/outputs converging in the medial central nucleus, the sublenticular extended amygdala, and the posterior lateral bed nucleus of the stria terminalis. The proportion of CRF+ outputs is $>50 \%$, and mainly targets the Al0 parabrachial pigmented nucleus (PBP) and A8 (retrorubal field, RRF) neuronal subpopulations, with additional inputs to the dorsal A9 neurons. CRF-enriched CEA-DA projections are positioned to influence outputs to the 'limbic-associative' striatum, which is distinct from striatal regions targeted by DA cells lacking CEA input. We conclude that the concept of the CEA is supported on connectional grounds, and that CEA termination over the PBP and RRF neuronal populations can influence striatal circuits involved in associative learning.
\end{abstract}

Neuropsychopharmacology (2017) 42, I563-1576; doi:I0.1038/npp.2017.38; published online 22 March 2017

\section{INTRODUCTION}

The central extended amygdala (CEA) is a forebrain structure that mediates various stress-induced behaviors. It includes the lateral bed nucleus of the stria terminalis (BSTL), the central amygdala nucleus (CeN), and the cellular streams that join them in the basal forebrain (ie, the sublenticular extended amygdala (SLEAc)) (Alheid and Heimer, 1988). The CEA is distinguished in part by its high content of neuropeptides, including corticotrophin-releasing factor (CRF), a modulator of stress responses. The CEA's well-delineated role in stress behaviors such as freezing and startle occurs via its position as a conduit between the amygdala, and hypothalamus and brainstem effector sites (see (Ulrich-Lai and Herman, 2009)). Stressful experiences also precipitate changes in goal-directed responses, including

\footnotetext{
*Correspondence: Dr IL Fudge, Departments of Neuroscience and Psychiatry, University of Rochester Medical Center, 601 Elmwood Avenue, Box 601, Rochester, NY |4642, USA. Tel: +I 585273 2028, Fax: + I 585754 5336, E-mail: Julie_Fudge@urmc.rochester.edu Received 17 June 2016; revised 8 February 2017; accepted 12 February 2017; accepted article preview online 21 February 2017
}

maladaptive responses such as drug seeking, impaired social responses, and compulsive behavior suggesting CEA effects on striatal circuits (Koob et al, 1998; Krishnan et al, 2007; Mantsch et al, 2016; Radley et al, 2015). The CEA substructures in both rodent (eg, (Zahm et al, 2011)) and primate (Fudge and Haber, 2000, 2001) project to the dopamine (DA) system with possible consequences for programming complex behaviors through DA-striatal paths.

The striatum mediates specific behavioral responses based on its division into functional zones, as determined by topographically organized cortical inputs. The ventromedial striatum receives input from classic 'limbic' structures, which overlaps partially with inputs from association cortex that terminate more centrally. Associative cortical inputs in turn partially overlap with afferents from sensorimotor cortex, which project dorsolaterally (Calzavara et al, 2007). DA neurons densely innervate the entire striatum, but do so in a feed-forward series of ascending loops (Haber et al, 2000). The DA subpopulations not only differentially innervate the striatal subregions but are also physiologically heterogeneous with respect to both their intrinsic firing and coding properties (Beier et al, 2015; Lammel et al, 2011; Lerner 
et al, 2015; Margolis et al, 2008). Although many DA neurons code whether stimuli are more or less rewarding compared to expected value, giving rise to a prediction error or 'teaching' signal (value coding) (Kobayashi and Schultz, 2008; Schultz et al, 1993), some DA neurons signal the biological relevance (salience) of both reward and nonreward predicting stimuli (salience coding) (Matsumoto and Hikosaka, 2009; Matsumoto and Takada, 2013). While valuecoding DA neurons facilitate approach behavior, saliencecoding neurons may have a different role in complex behaviors such as orienting, or preparing strategies to avoid potentially aversive cues (Brischoux et al, 2009; BrombergMartin et al, 2010; Matsumoto and Hikosaka, 2009; Pignatelli and Bonci, 2015; Volman et al, 2013). The anatomic position of DA neurons in monkeys and humans correlates with these physiological properties, and behavioral responses to aversive and appetitive stimuli (Matsumoto and Hikosaka, 2009; Matsumoto and Takada, 2013; Pauli et al, 2015). The anatomic organization and striatal outputs of DA subpopulations may therefore provide insight into circuit properties in higher primates. Further evidence for circuit delineation as a predictor of DA cell physiology has recently arisen in mouse models, which show that specific input/output circuits are associated with differential firing properties across the midbrain DA system (Beier et al, 2015; Lammel et al, 2011; Lerner et al, 2015; Margolis et al, 2008).

On the basis of evidence that DA subpopulation function may be tied to specific anatomic position and/or connectivity, we used anatomic criteria to define distinct DA subpopulations in nonhuman primates, and mapped the CEA-DA-striatal pathway. Using paired injections in the same animal, and bidirectional tracer studies, we found that large open loops arise from specific nuclei in the amygdala to target the posterior BSTL (BSTLP), the SLEAc, and medial $\mathrm{CeN}$ (CeM). In turn, the entire BSTLP-SLEAc-CeM continuum-enriched in CRF-positive cells-largely terminates over the PBP of the A10 neurons, and over the retrorubal field (RRF, A8 group), with more modest input to the dorsal SNc. In contrast, there was relatively less input to classic midline ventral tegmental area subnuclei (VTA). Finally, using bidirectional injections into the midbrain DA neurons, we found that $\mathrm{PBP}$ and A8 subregions that received CEA input projected specifically to striatal sectors where limbic and association cortical inputs converge, suggesting that the CEA-DA path enables salience information to influence cognitive programs.

\section{MATERIALS AND METHODS}

\section{Overall Design}

Two groups of animals were used: (Study 1) to study the scope of anterograde input to the DA system, tracers with bidirectional properties Lucifer yellow (LY), Fluorescein (FS), and Fluororuby (FR) (Molecular Probes, Temecula, CA, USA) were pressure injected into the BSTL and CeN. The distribution of labeled fibers across the mediolateral and rostrocaudal extent of the ventral midbrain was then mapped To assess the relative overlap of anterogradely labeled fibers within specific DA subpopulations, adjacent sections through the midbrain, labeled for markers of the dorsal and ventral tier, were used (see Analysis, below). (Study 2) using anterograde results from Study 1 as a guide, we placed bidirectional and retrograde tracer injections into relevant DA neuronal subpopulations. Thirteen injections of the bidirectional tracers LY, FS, FR or the retrograde tracer wheat germ agglutinin-horse radish peroxidase (WGA-HRP) were placed at various rostrocaudal and mediolateral sites in ventral midbrain. In a subset of cases with ventral midbrain injections, one or more anterograde injections were also placed into the amygdala (using tracers that were different from those injected into the ventral midbrain). Cases with paired amygdala/ventral midbrain injections $(n=18$ injection pairs) were used to determine the general pattern of overlap between anterogradely labeled fibers from the amygdala and DA-projecting cells in the CEA across all animals. We then analyzed specific the patterns of overlap resulting from paired injections placed within individual animals. We also determined the proportion of retrogradely labeled cells in the CEA that co-contain CRF-immunoreactivity(IR), analyzing cases according to injection site position within the DA subpopulations. Finally, using individual cases with bidirectional tracer injections into the ventral midbrain subpopulations, we determined the specificity of nigro-striatal paths associated with CEA input.

\section{Surgeries}

Fourteen old-world male monkeys between the ages of 3 and 8 years (World Wide Primates, Tallahassee, FL, USA; Three Springs Laboratories, Pekaski, PA; Labs of Virginia, Yemassee, SC; Alpha Genesis, Yemassee, SC, USA) received multiple injections of neuronal tracers. To reduce animal use, some of the injections placed in the amygdala and CEA (Study 2) were mapped as parts of other studies (Cho et al, 2013; Decampo and Fudge, 2013; Oler et al, 2016). All experiments were carried out in accordance with National Institute of Health guidelines. Experimental design and techniques were aimed at minimizing animal use and suffering and were reviewed by the University of Rochester Committee on Animal Research. For Study 1, we placed small injections $(40 \mathrm{nl})$ of LY (10\%, Molecular Probes, Eugene, OR), FR (4\%, Molecular Probes), and FS (10\%, Molecular Probes) into the BSTL and CeN. For Study 2, we placed bidirectional tracer injections (LY, FR, FS) or the retrograde tracer WGA-HRP into various levels of the ventral midbrain. For some animals, additional anterograde injections were placed into the amygdala with one of the bidirectional tracers not used in the ventral midbrain injections ( $40 \mathrm{nl}$ of LY, FR, FS), or $200 \mathrm{nl}$ of tritiated amino acids (AA) (1:1 ratio of tritiated proline and leucine: PerkinElmer, Boston, MA, USA). See Supplementary Methods for further details.

\section{Single Label Immunocytochemistry}

Tracer IR. Sections (1:8) through the brain were immunostained for each tracer in each animal. Optimal dilutions were established in condition-setting experiments before use. See Supplementary Methods for details. Detection of these tracer molecules in tract-tracing has been extensively documented in studies showing that there is no crossreactivity of antibodies to FR, FS, and LY (Cho et al, 2013; Haber et al, 2000). In our experience FR, FS, LY and AA have 
similar anterograde properties, and are sensitive indicators of terminal fields when survival is between 10 and 14 days. In the retrograde studies, FR, FS, and LY have similar retrograde properties; when placed in identical sites, WGA results in more retrogradely labeled cells than FR, FS, and LY injections, but results in similar distribution patterns.

Calbindin D28k (CaBP), G-protein-regulated inwardrectifier potassium channel 2 (Girk2), CRF, and tyrosine hydroxylase (TH) IR. To determine the boundaries of the DA subpopulations, adjacent sections were immunostained for TH (a marker for DA in the ventral midbrain(Pearson et al, 1983)), CaBP (a marker of the 'dorsal tier' DA subpopulation) (Gaspar et al, 1993; Haber and Fudge, 1997; Lavoie and Parent, 1991; McRitchie et al, 1996; Yamada et al, 1990), and Girk2. Girk2-IR (and mRNA) is relatively higher in the A9 neurons of the 'ventral tier' (although it is not exclusively expressed there) (Chung et al, 2005; Reyes et al, 2012; Schein et al, 1998). While the nomenclature of the DA subpopulations has varied with time (see Analysis), the use of CaBP-IR to denote a continuum of dorsally located $\mathrm{TH}$ positive cells is established across species.

CaBP-IR was also used to determine the boundary between the primate globus pallidus (CaBP-positive) and SLEAc (Cote et al, 1991) in the retrograde component of Study 2. The corridor occupied by the SLEAc has low CaBPIR, as well high levels of neuropeptides such CRF and neurotensin, among others (eg, (Decampo and Fudge, 2013)). See Supplementary Methods for technical details.

Acetylcholinesterase (AChE) staining. Subdivisions of the CEA were assessed AChE using the Geneser technique (Geneser-Jensen and Blackstad, 1971) (see Figure 1a-g). This stain and its relationship to neuropeptide immunoreactivity of CEA subdivisions has been previously established in human(Heimer et al, 1999) and nonhuman primate (Decampo and Fudge, 2013).

\section{Double Label Immunofluorescent Cytochemistry}

$C R F / C a B P, C R F / T H, C R F /$ tracer. In Study 2, the relationships between CRF-positive fibers and the DA subpopulations were assessed with $\mathrm{CRF} / \mathrm{TH}$ and CRF/CaBP immunofluorescence. The proportion of tracer-labeled cells in the CEA that co-expressed CRF-IR was also determined in Study 2. 1:24 sections (from tracer injected cases) were fluorescently labeled sequentially with CRF and anti-wheat germ agglutinin (WGA) antibodies. (Sections containing the tracers FS and FR were processed only for CRF-IR, as these tracers have fluorescent properties.) See Supplementary Methods for additional details.

\section{Analyses}

Subdivision of the DA subpopulations. The A10 neurons comprise the VTA and its various subnuclei, and the contiguous dorsal expanse of TH-positive neurons that stretch under the red nucleus known as the PBP. The PBP is in the 'dorsal tier', and was previously grouped in the A9 subpopulation (Cho and Fudge, 2010; Francois et al, 1999), based on classic studies that referred to this region as the 'pars dorsalis' $(\Upsilon$ group) of the A9 neurons (Olszewski and
Baxter, 1954). However, accumulated evidence on the cellular and histochemical features across species now indicate that the PBP is more properly considered part of the A10 group (Halliday and Tork, 1986; McRitchie et al, 1996; Olszeskwi and Baxter, 2014; Root et al, 2016). The A10 DA cells have high levels of CABP (Haber et al, 1995), and are considered part of the 'dorsal tier'. In contrast, the majority of A9 neurons of the substantia nigra, pars compacta $(\mathrm{SNc})$ lack $\mathrm{CaBP}-\mathrm{IR}$, and contain relatively higher levels Girk2-IR. They are referred to as the 'ventral tier'. It is important to appreciate, however, that some Girk2-IR cells occupy the dorsal tier (Reyes et al, 2012), and some CaBP-IR cells are found in the 'ventral tier'(McRitchie and Halliday, 1995). The ventral tier A9 neurons have been divided into medial, dorsal, lateral and ventral groups by McRitchie et al (1996). The A8 neurons emerge laterally and are most prominent in the caudal third of the midbrain, and like the A10 neurons, are CaBP-positive and are included in the 'dorsal tier'.

CRF/tracer in the CEA-DA path. Immunofluorescent images were collected on a Leica DM 5500B epifluorescent microscope at $\times 40$ magnification (HCX PL APO; 40X/1.30 Oil) mounted with a Leica DFC 3654-FX digital camera. The following filter cubes were used: L5 (Alexa Fluor 488; L5 ET, k; BP480/40; Leica) TX2 (AlexaFluor 568; TXR ET, k; BP 560/40; Leica) and Y5 (AlexaFluor 647; Y5 ET, k; BP 620/60; Leica) were used. Fluorescent images were captured using the Leica Application Suite software (LASX; v. 2.0) and postprocessing done using the LASX 3D Power Package Following Z-series collection ( 0.2 um per step; $~ 25$ um per ROI), images were further deconvolved to removed background fluorescence and amplify specific cellular labeling (Process: Blind with 15 iterations). De-convoluted images were analyzed using the LASX Software. Ten $\times 40$-magnified regions within the BSTL and CeN were analyzed within each case. Ten randomly sampled cells in each $\times 40$ field (100 cells per case) were reviewed in each channel and the absence or presence of label was recorded. Cell bodies that were filled with stain with clear cellular borders were included: if the cell soma was filled with either bright green or bright red fluorescent label it was considered single-labeled. Only cells that contained yellow throughout the soma were considered double labeled. The neuropil in the BSTL and CeN contained both CRF-positive and tracer-positive processes, as expected, and there were punctate contacts between fine processes and some cell soma, seen as tiny specks of label at the cell perimeter. For example, cell bodies that were homogeneously filled with green, indicating a tracer-labeled cell, might have CRF-positive (red) fibers passing by the soma (seen as speckles of red), or contacting the soma (seen as specks of yellow on the cell perimeter). The presence of punctate elements near or on the cell surface was interpreted as intrinsic contacts between cells, and did not alter criteria for single or double-labeled cells. Statistical analysis was performed using Prism VI statistical analysis software (GraphPad Software, Inc., La Jolla, CA). All values reported are the mean \pm SEM. For all analysis, significance was based on $\alpha=0.05$. When comparing between groups, significance was determined using two-tailed unpaired Student $t$-tests. 
a

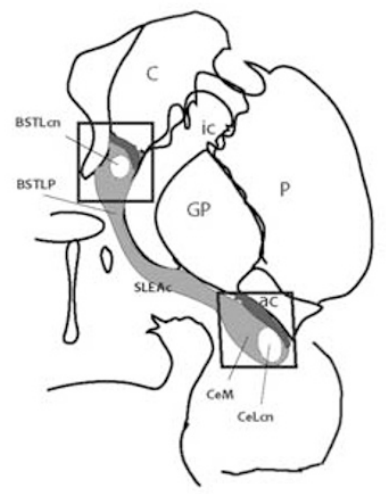

b

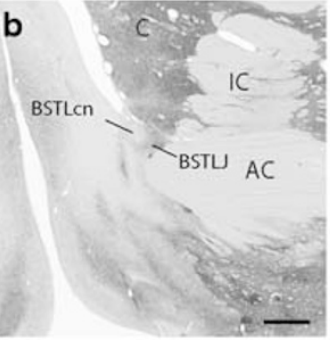

e

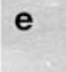

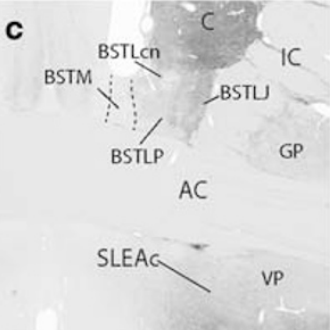

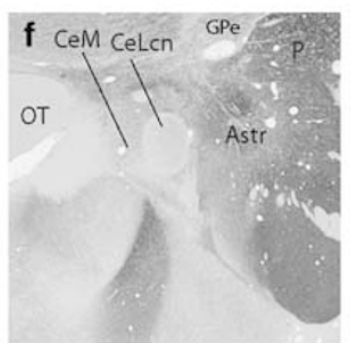

d
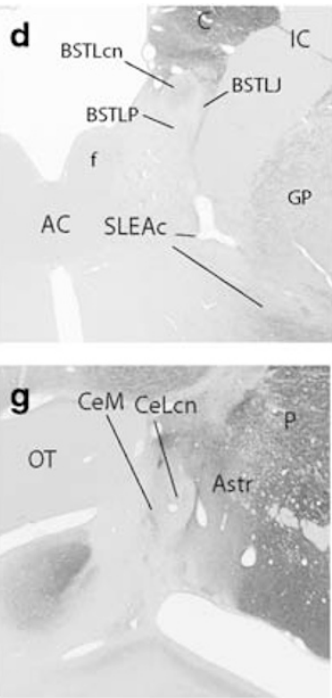

h

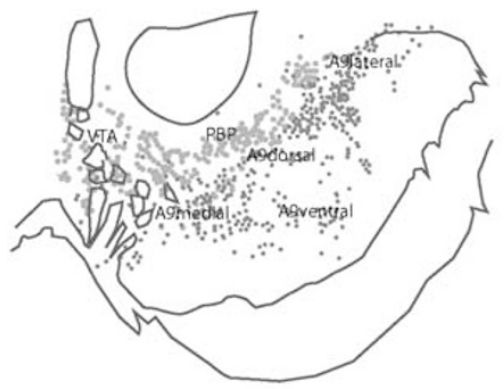

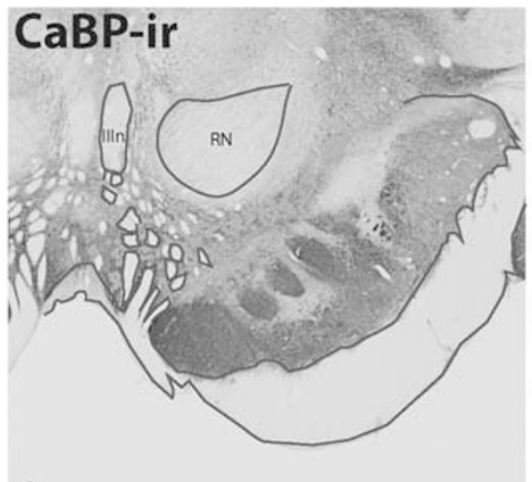

i

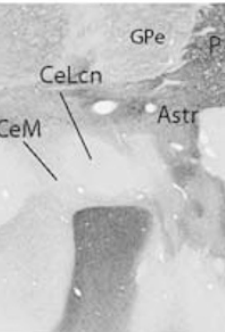

Girk2-ir

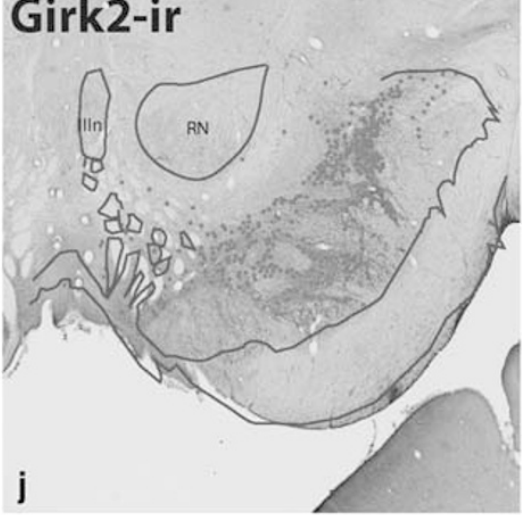

Figure I ( $(a-g)$ The subdivisions of the BSTL $(a, b-d)$ and CeN (a, e-g) in the nonhuman primate in sections stained with AChE. (h-j) Subdivisions of the primate ventral midbrain DA neurons. Adjacent sections through the ventral midbrain immunostained for CaBP (i) and Girk2 (j). Cell bodies containing CaBP-IR (green) and Girk2-IR (pink) were charted and are overlaid on their respective images in $\mathrm{i}$ and $\mathrm{j}$, and on each other in $\mathrm{h}$, matching landmarks, to show the general organization of the DA subpopulations. Illn, third nerve; AC, anterior commissure; Astr, amygdalostriatal area; BSTLcn, bed nucleus of the stria terminalis, lateral central subdivision; BSTLJ, bed nucleus of the stria terminalis, juxtacapsular subdivision; BSTLP, bed nucleus of the stria terminalis, lateral posterior subdivision; BSTLM, bed nucleus of the stria terminalis, medial subdivision; C, caudate nucleus; CeLcn, central nucleus, lateral central subdivision; CeM, central nucleus, medial subdivision; f, formix; GP, globus pallidus; GPe, globus pallidus, extemal division; IC, intemal capsule; OT, optic tract; P, putamen; RN, red nucleus; SLEAc, sublenticular extended amygdala, central subdivision; VP, ventral pallidum. Scale bar, I mm. A full color version of this figure is available th the Neuropsychopharmacology journal online.

\section{RESULTS}

\section{Organization of CEA Subdivisions in Nonhuman Primate}

The BSTL is the rostral pole of the CEA, located beneath the ventral caudate nucleus, and extends under and behind the decussation of the anterior commissure (Figure 1a-d). The CeN resides in the caudal half of the dorsal amygdala (Figure 1e-h). We use the nomenclature of Heimer (Heimer et al, 1999) and Martin (Martin et al, 1991) (these CEA designations are also used in rodent (McDonald, 2003) although multiple naming systems exist (Dong et al, 2001)). The posterolateral subdivision of the BSTL (BSTLP) and medial subdivision of the CeN (CeM) have a heterogeneous cell population, including 'pallidal-like' cells, which continue without interruption into the central SLEAc. The SLEAc stream of cells in turn continues its trajectory under the globus pallidus. The BSTLP and CeM each surround a central lateral subdivision, or 'core' (BSTLen and CeLcn, respectively). Both the BSTLcn and CeLcn have relatively low acetylcholinesterase (AChE) staining, and high levels of neuropeptides (Decampo and Fudge, 2013; Heimer et al, 1999; Martin et al, 1991). A 'striatal-like' zone that is relatively high in AChE, similar to the neighboring striatum, is also found in both the BSTL and CeN. In the BSTL, the striatal-like zone is the juxtacapsular subdivision (BSTLJ), and in the CeN, it is the amygdalostriatal area (Astr). Both of these regions extend a 'capsule' surrounding the BSTLcn and CeLcn, but in the monkey this 'capsular' subdivision mostly is thin and fibrous with relatively few cellular elements.

\section{Structural Heterogeneity of DA System in Nonhuman Primate}

The majority of DA neurons in the VTA, including those of the contiguous PBP (Figure 1h), are CaBP-positive, as are many DA neurons in the RRF. These cells comprise the 'dorsal tier' neurons of the ventral midbrain DA system. In 
contrast, the ventral tier neurons of the pars compacta are mostly CaBP-negative but contain high concentrations of Girk2-IR (Figure 1j). When charted, Girk2-positive neurons revealed the organization of the A9 medial, dorsal, ventral and lateral regions as previously documented (McRitchie et al, 1996)(Figure 1h.) Girk2-positive cells were also found in the A10 and A8 subpopulations in a less homogeneous distribution. In the caudal half of the midbrain (not shown), the $\mathrm{A} 8$ neurons are $\mathrm{CaBP}+$ and lie dorsomedial to the medial lemniscus, and lateral to the VTA, with CaBP-negative ventral tier (A9) neurons occupying a relatively small region ventrally.

\section{Study 1: The BSTL and CeN Mainly Target the PBP and RRF}

We first examined anterogradely labeled fibers after injections into the two 'poles' of the CEA: four injections into the BSTL and four into the CeN (Study 1). All injections into the BSTL and CeN subdivisions resulted in labeled fibers over the dorsal tier (A10 and A8) neurons, with encroachment on medial, dorsal, and lateral regions of the ventral tier (Figure 2, A9 neurons, in gray). Although smaller injections resulted in sparser concentrations of labeled terminals overall, the distribution of labeled fibers in the ventral midbrain was very similar for all injection sites. Within the dorsal tier, anterogradely labeled fibers terminated most densely over the PBP and the A8 (RRF) neuronal groups, while much of the classic VTA had a relatively light distribution of tracer-containing fibers. BSTL injections resulted in a slightly greater density of labeled fibers in the rostromedial VTA compared with cases with $\mathrm{CeN}$ injections. This suggested a slight overall rostrocaudal (BSTL-CeN) to medial-lateral (ventral midbrain) shift in the afferent projection from the CEA as a whole. Yet for all BSTL and $\mathrm{CeN}$ injections, the $\mathrm{PBP}$ and $\mathrm{RRF}$ received the highest density of labeled fibers.

\section{Study 2: PBP and A8 Inputs Arise From Specific CEA Subdivisions}

To visualize which CEA subdivisions provide input to the PBP and A8 neurons, tracers with bidirectional and retrograde properties were injected into the $\mathrm{PBP}$ and $\mathrm{A} 8$ subpopulations at different rostrocaudal and mediolateral levels ( $n=13$, Figure 3 ). There were labeled cells in the CEA following every injection that included either the PBP or A8 neurons, and relatively few labeled cells after injections confined to the A9 ventral tier neurons (cases J20FR, J14WGA), confirming anterograde results (Figure 4). The majority of labeled cells following injections into PBP and A8 neurons were in the BSTLP, SLEAc and CeM, and were distributed in a relatively continuous fashion (Figure $4 \mathrm{a}-\mathrm{e}$ ). In the SLEAc, tracer-labeled cells were medium-sized

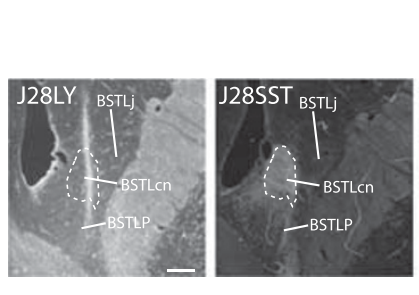

a

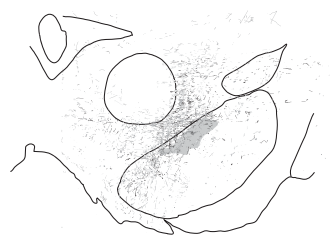

C

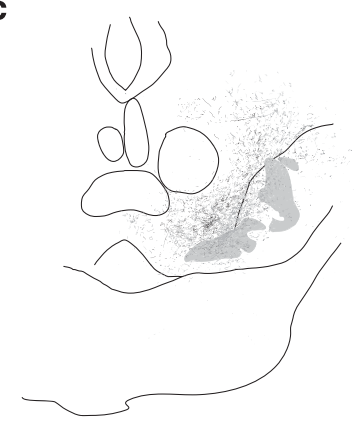

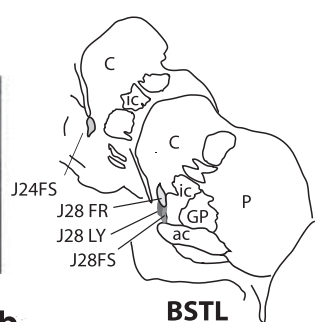

b

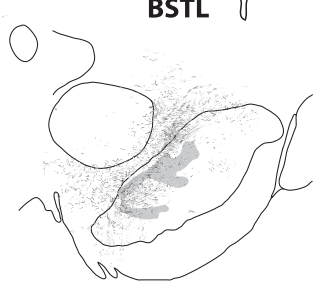

d

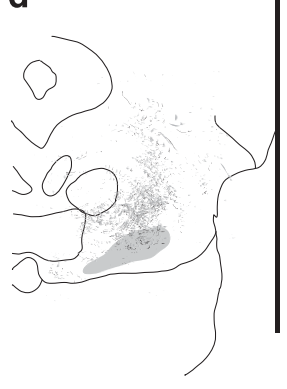

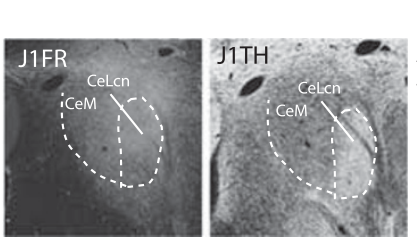

a'

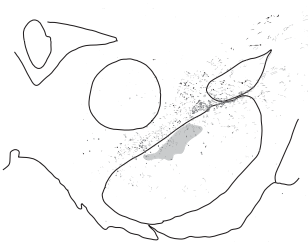

c'

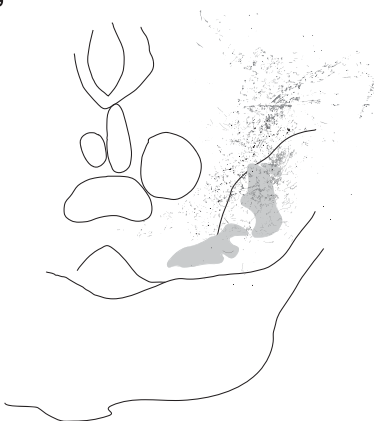

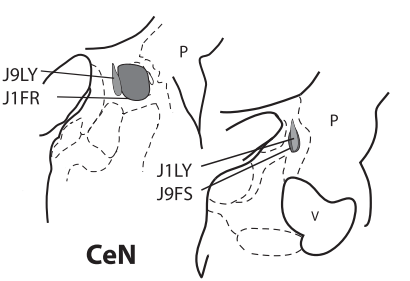

b'

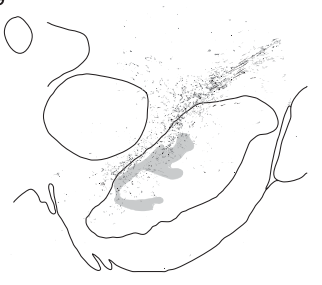

d'

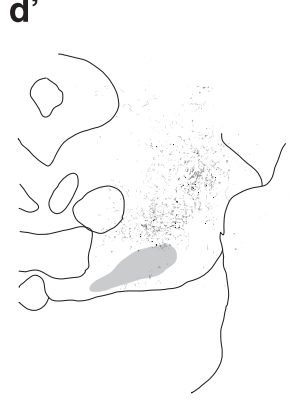

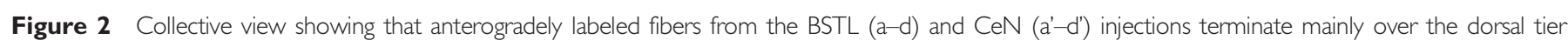

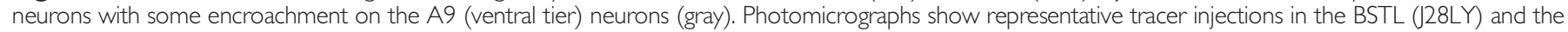

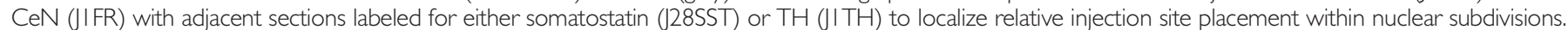

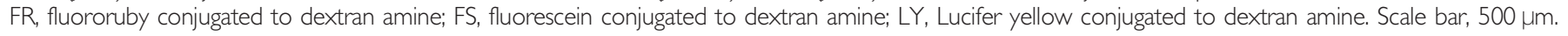




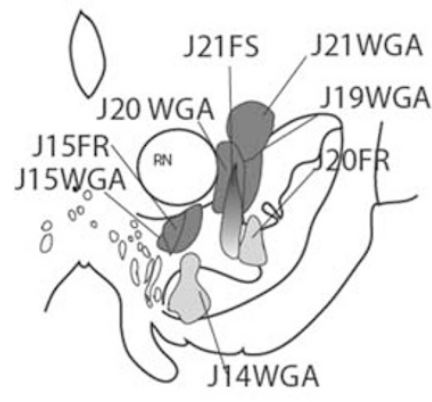

rostrocentral

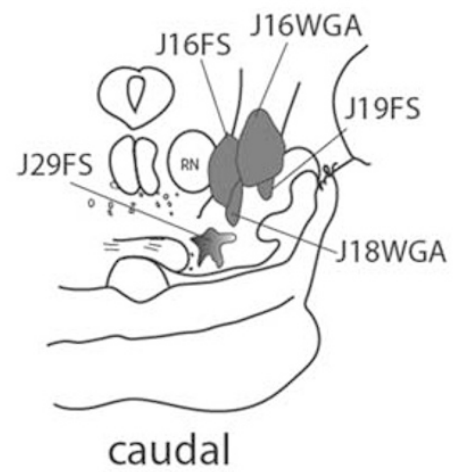

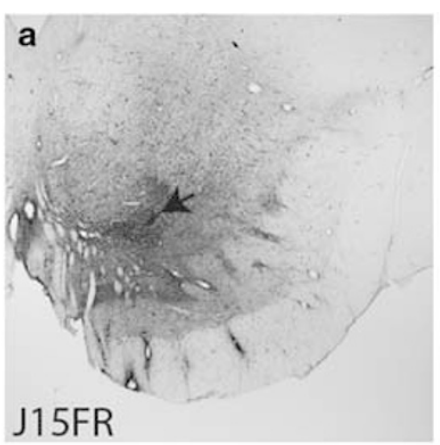
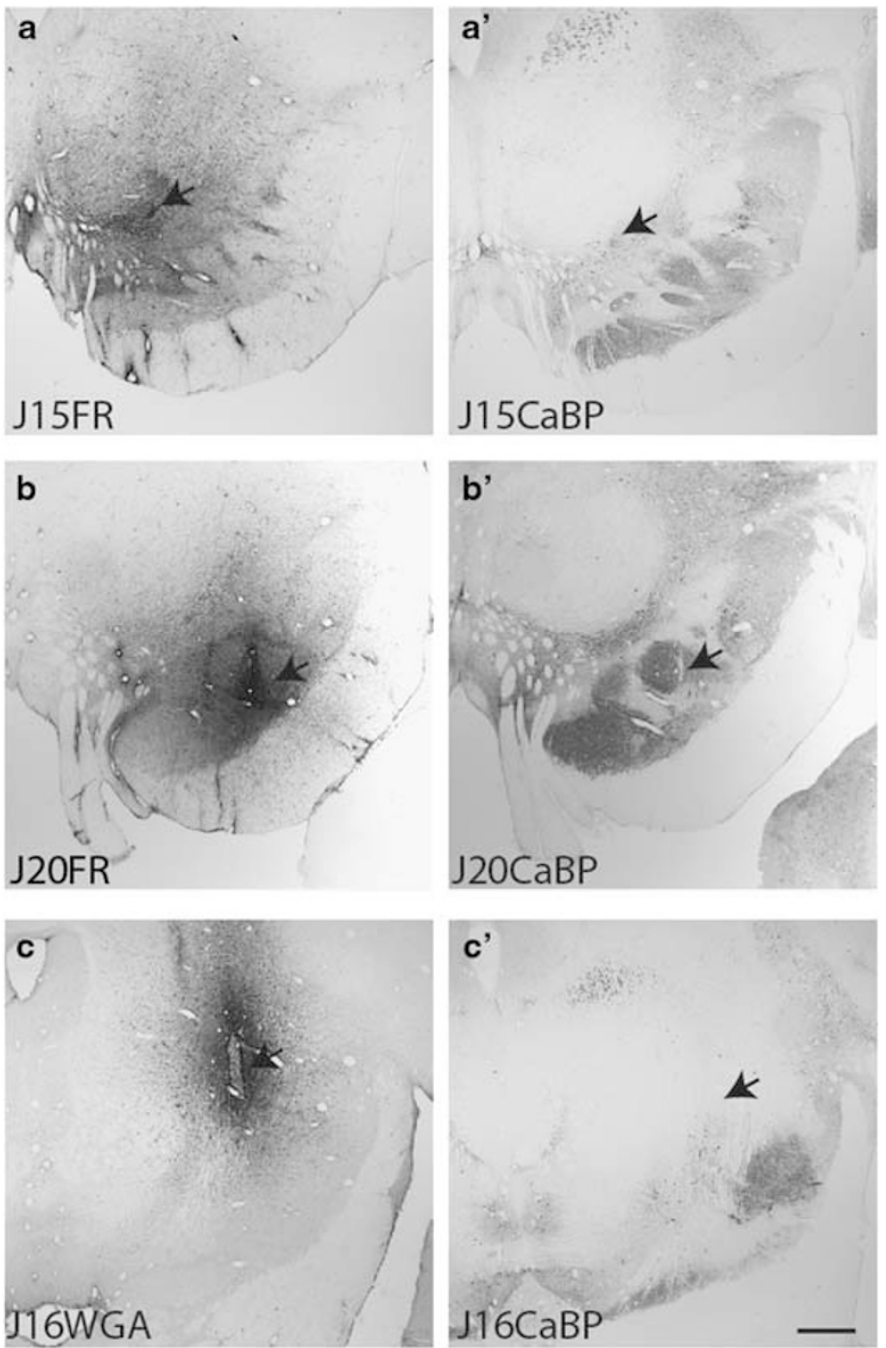

Figure 3 Schematic representation of all injections into the ventral midbrain. Injections that include the PBP or A8 neurons are in dark gray and injections outside these neuronal subpopulations are in light gray. Panels show representative photomicrographs (a-c) of retrograde/bidirectional tracer injections into the DA neuronal subpopulations and adjacent sections labeled with CaBP (a'-c') to determine boundaries. FR, fluororuby conjugated to dextran amine; FS, fluorescein conjugated to dextran amine; WGA, wheat germ agglutinin-horse radish peroxidase. Scale bar, 500 um.

neurons that surrounded the large cholinergic cell islands. The BSTLJ and ventral caudate, and Astr and ventromedial putamen, also had moderate numbers of retrogradely labeled cells. In contrast, there were relatively few labeled cells in the BSTLen and CeLcn following any injection (Figure 4a-g).

\section{The CeM/SLEAc/BSTLP Receive Broad Input from the Basal Nucleus, Accessory Basal Nucleus and Amygdalohippocampal Area}

We examined 16 cases of injections into the lateral, basal, and accessory basal nuclei and amygdalohippocampal area to determine the pattern of anterograde fiber distribution in all CEA subdivisions. Collective anterograde results are schematized in Figure 5a. All injections into the basal and accessory basal nuclei and the amygdalohippocampal area resulted in discontinuous patches of fine, beaded fibers throughout the CeM, BSTLP and SLEAc (gray). Only injections into the ventromedial basal nucleus and corticoamygdaloid transition region (pink) resulted in dense concentrations of labeled fibers in the BSTLen and CeLcn, as well as labeled fibers to the CeM, SLEAc, and BSTLP (Figure $5 \mathrm{a}$ and $\left.\mathrm{c}, \mathrm{c}^{\prime}\right)$. These amygdala regions are transition zones between the periamygdaloid cortex (PACs) and entorhinal cortex and hippocampus in the primate (and are also referred to as the amygdalopiriform area (De Olmos, 1990) and sulcal division of the PACs (Price et al, 1987)). The ventromedial basal nucleus and corticoamygdaloid transition area have also been likened to the amygdalopiriform area in rodents although, in contrast to rodents, they are not adjacent to the piriform cortex. The relatively dense and focused inputs to the BSTLen and CeLcn from these transitional zones resembles amygdalopiriform area projections in the rat (McDonald et al, 1999; Shammah-Lagnado and Santiago, 1999). There were few to no anterogradely labeled fibers in the CEA after several large injections into the lateral nucleus, except for patches of anterogradely labeled fibers in the BSTLJ and Astr. 


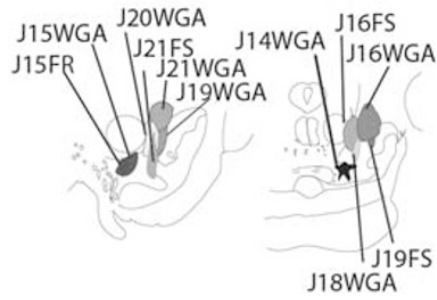

c

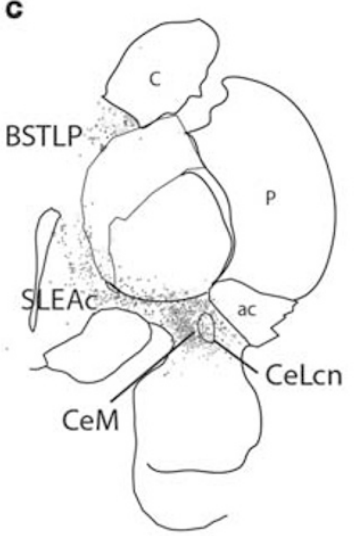

a

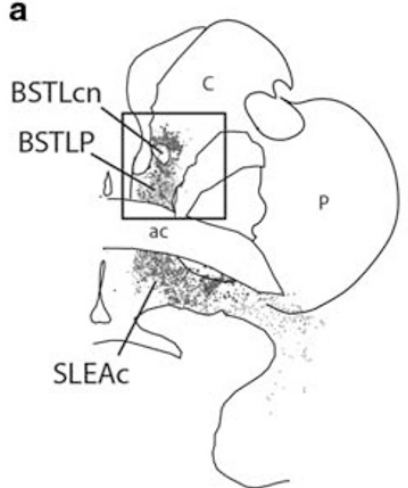

d

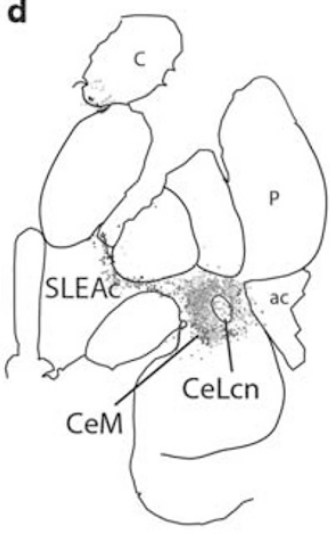

b

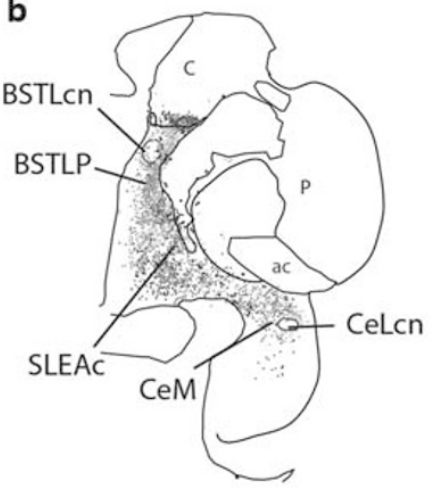

e

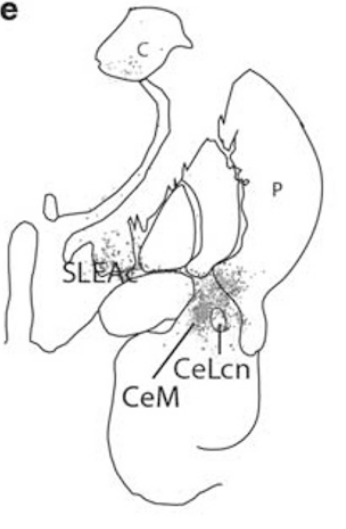

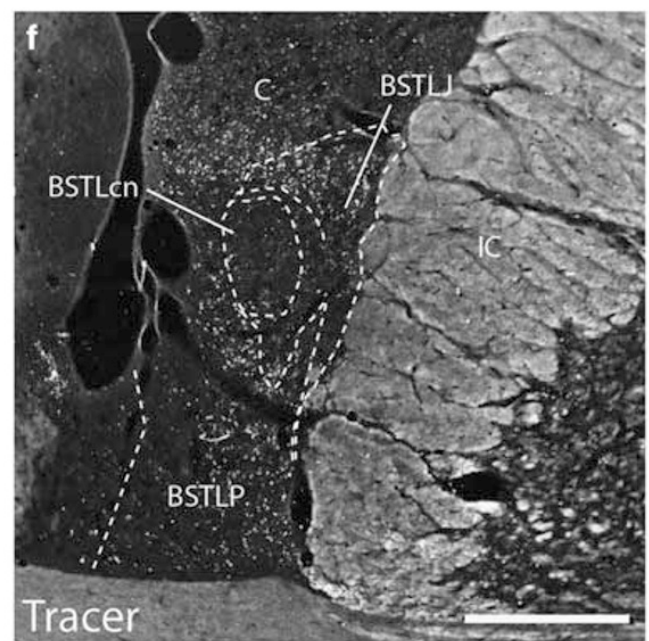

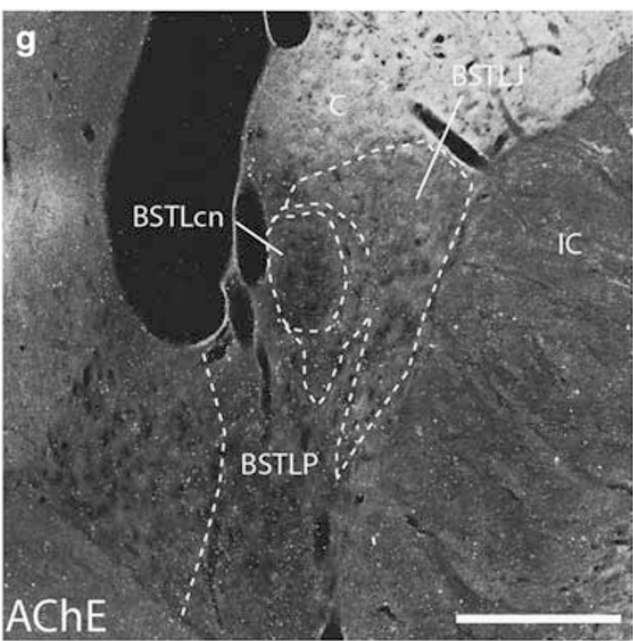

Figure 4 Collective view of retrogradely labeled cells in the CEA following all injections that encompassed the PBP and A8 subpopulations (a-e). All injections result in a continuous stream of labeled cells in the CeM-SLEAc-BSTLP, but fewer labeled cells in the BSTLcn and CeLcn. (f) Photomicrograph of the pattern of retrogradely labeled cells in the BSTL in an individual case (JI5WGA) and an adjacent section (g) stained with AChE. Scale bar, Imm.

The distribution of labeled fine fibers with boutons, originating from injections in the basal and accessory basal nuclei and amygdalohippocampal area, aligned with labeled cells resulting from retrograde tracer injections into the ventral midbrain that included the $\mathrm{PBP}$ and $\mathrm{A} 8$ subregions (Figure $5 \mathrm{a}$ and $\mathrm{b}$ ). Although the precise position of overlapping retrogradely labeled cells and anterogradely labeled terminals within the BSTLP-SLEAc-CeM varied depending on the location and size of individual injections, overlapping patches of labeled cells and fibers were found in all cases along the entire BSTLP-SLEAc-CeM trajectory (eg, case J15: Figure 5e-k). The BSTLcn and CeLcn had a relatively light distribution of retrogradely labeled cells following all nigral injections, and dense concentrations of anterogradely labeled fibers after injections into the ventral basal nucleus and corticoamygdaloid area (CTA) (Figure 5c'). Therefore, the ventral basal nucleus and CTA circuit to the BSTLen and CeLcn did not have a direct effect on CEA outputs to the DA system. Since the BSTLen and CeLcn are intrinsic modulators of CEA outputs (Pitkanen et al, 1997), this subcircuit can indirectly modulate the PBP and A8 neuronal subpopulations via intrinsic control of BSTLP-SLEAc-CeM efferents. 

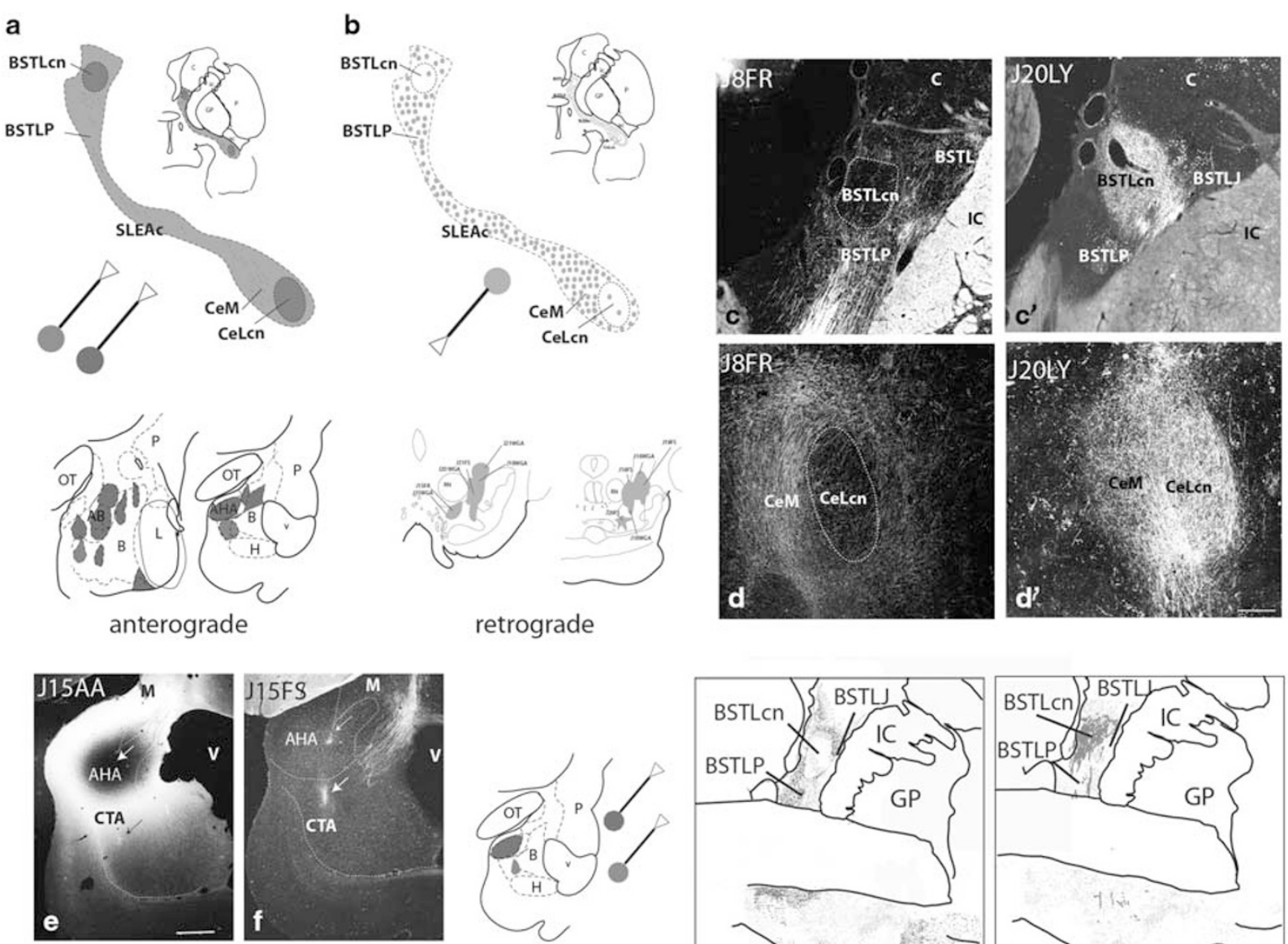

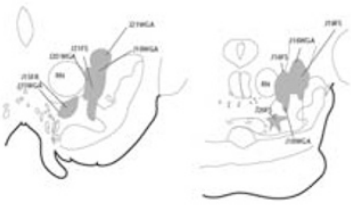

retrograde
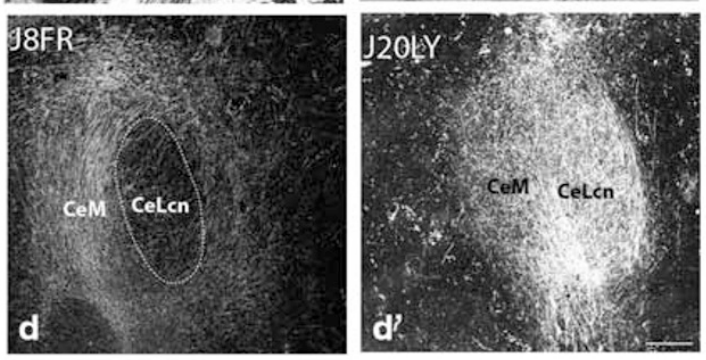

J15WGA

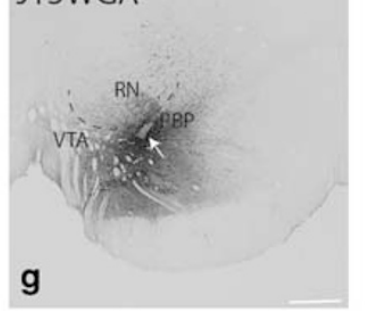

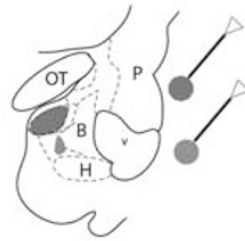

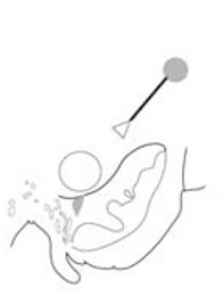

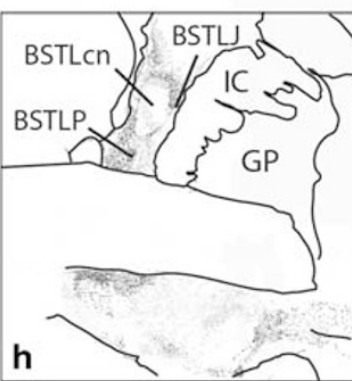
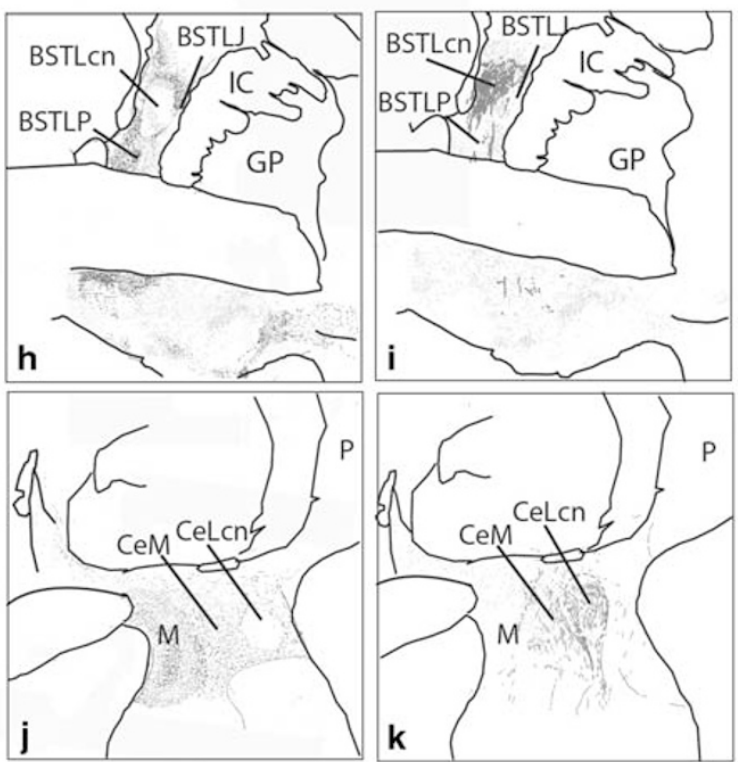

Figure 5 (a, b) Schematic representations depicting collective inputs from the amygdala to CEA subdivisions (a), and collective outputs from the CEA subdivisions to the PBP and A8 subpopulations (b). In a, all injections (gray and pink) resulted in anterogradely labeled fibers along the CeM-SLEAc-BSTLP. Only injections into the ventromedial basal nucleus/CTA region (pink) resulted in additional strong inputs to the BSTLcn and CeLcn. This is illustrated in individual cases. (c-d) Case J8FR (basal nucleus injection) in which anterogradely labeled fibers are found in the BSTL and CeM, with relatively few in the BSTLcn and CeLcn. (c', d') Case J20LY, with an injection in the ventromedial basal nucleus/CTA, results in additional strong input to the BSTLCn and CeLcn. (e-g). Relationships between input/outputs demonstrated in three injections in the same animal (JI5). (h-k). Anterograde tracer from the amygdalohippocampal area (AHA, JI5AA) in black, anterograde tracer from the ventromedial basal nucleus//CTA is shown in pink (II5FS), and retrogradely labeled cells from the medial PBP (II5WGA) in green seen at two levels of the BSTL ( $h-i)$ and $C e N(j-k)$. AB, accessory basal nucleus; AHA, amygdalohippocampal area; B, basal nucleus; BSTLcn, bed nucleus of the stria terminalis, lateral central division; BSTLJ, bed nucleus of the stria terminalis, lateral juxtacapsular division; BSTLP, bed nucleus of the stria terminalis, lateral posterior division; C, caudate; CeLcn, central nucleus, lateral central division; CeM, central nucleus medial subdivision; CTA, corticoamygdaloid transition area; GP, globus pallidus; H, hippocampus; IC, internal capsule; L, lateral nucleus; M, medial nucleus; OT, optic tract; P, putamen; PBP, parabrachial pigmented nucleus; RN, red nucleus; SLEAc, sublenticular extended amygdala, central subdivision; VTA, ventral tegmental area. Scale bars, 500 um. A full color version of this figure is available at the Neuropsychopharmacology joumal online.

\section{CRF Content in CeM/SLEAc/BSTL Projection to the DA Neuronal Subpopulations}

The CeM, SLEAc and BSTLP contain CRF-labeled cells (Bassett and Foote, 1992; Cummings et al, 1983). In contrast to the dense concentrations of CRF neurons in the BSTLcn and CeLcn, CRF-positive cells in the CeM-SLEAc-BSTLP corridor are relatively diffusely distributed over larger areas, and are difficult to appreciate in single-plane and low power views. To adequately estimate the proportion of tracerpositive cells that contained CRF-IR, we sampled tracercontaining neurons through the $Z$-plane under high magnification $(\times 40)$ in five areas of the BSTLP and CeM in 

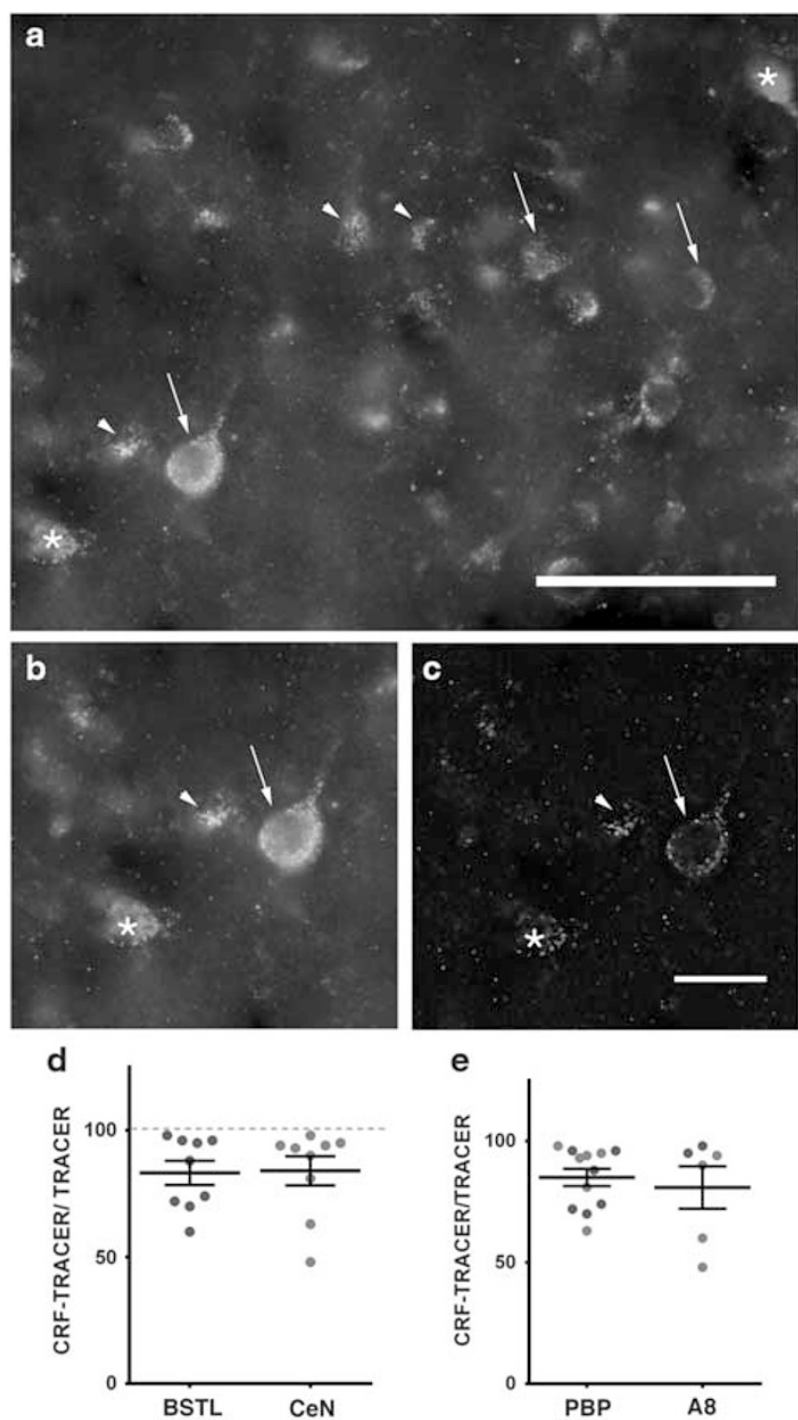

Figure $6 \mathrm{CRF}$ content in CeM/SLEAc/BSTL projections to the DA cells. (a) Representative example of CRF (red) and tracer labeling (green) in the BSTLP demonstrating the dense concentration of CRF neurons. Populations of single-labeled CRF cells (white asterisks), tracer-only labeled cells (white arrow) and dual labeled cells were found (white arrow head) in both the BSTL and CeN. High power images were assessed for quantification, before (b) and after (c) deconvolution. (d) Quantitative analysis of the proportion of CRF/tracer double-labeled cells in BSTL and CeN showed no significant difference. (e) Quantitative analysis of CRF/tracer labeled cells in BSTL (blue dots) and CeN (red dots) following injections into PBP or A8 showed no

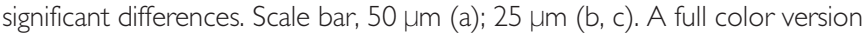
of this figure is available at the Neuropsychopharmacology journal online.

two adjacent sections (Figure 6a-c). Approximately $80 \%$ of tracer-labeled cells contained CRF-IR in both the BSTLP and $\mathrm{CeM}$, with similar proportions in each region (Figure $6 \mathrm{~d}$ and e, paired Student $t$-test, $P=0.8263$, df 8 ). There were also no significant differences in the proportion of CRF+tracer/ tracer labeled cells across PBP or RRF injections (Student's $t$-test, $P=0.6029$, df 16).

In control tissue from non-injected animals, CRF-positive fibers were densely distributed over the entire dorsal tier, including the midline nuclei of the VTA (Supplementary Figure 1). The mismatch between high levels of CRF-positive fibers, and the relatively low density of anterogradely labeled fibers in the medial VTA nuclei after BSTL and CeN injections (Study 1), suggests that CRF-containing cell populations outside the CEA provide innervation of the midline VTA nuclei. CRF-positive fibers in the PBP and RRF, which followed the same trajectory as anterogradely labeled fibers from the BSTL and CeN, formed fine, highly beaded fiber patches, with individual labeled fibers encircling and closely apposed to some TH-positive (and CaBPpositive) neurons (Supplementary Figures 1c, f, i and l).

\section{CEA-DA-Striatal Loops}

The pattern of anterogradely labeled fibers in the striatum was analyzed for five cases with bidirectional tracer injections encompassing different DA subpopulations. Four injections were placed to include the dorsal tier subregions that were overlapped by many anterogradely labeled fibers in Study 1: medial PBP (case J15FR, red), central PBP (case J21FS orange), and A8, RRF (case J29FSblack, case J19FS, pink). One injection was confined to the A9 ventral tier (J20FR, turquoise) (Figure 7). The PBP and A8 (RRF) injections resulted in labeled cells in the CeM-SLEAc-BSTLP continuum, and anterogradely labeled fibers in the rostral central striatum and ventrolateral shell of the nucleus accumbens (Figure $7 \mathrm{a}-\mathrm{c}$ ). The rostral ventral and medial shell of the nucleus accumbens was devoid of labeled fibers. The dorsolateral striatum was also without anterograde labeling. In the caudal striatum, labeled fibers were clustered in the ventromedial body of the caudate nucleus and the ventromedial putamen (Figure $7 \mathrm{~d}-\mathrm{g}$ ), while the dorsolateral caudate nucleus and putamen were devoid of labeled fibers. Conversely, the injection in A9 ventral tier resulted in few to no labeled cells in the CEA, and produced many dense aggregates of labeled fibers throughout the dorsolateral striatum at all rostrocaudal levels (Figure 7, top, a'-g'), avoiding the central and ventral striatum. Comparing striatal innervation at all rostrocaudal levels for the five cases revealed that there was little overlap between projections from DA neuronal subpopulations that receive CEA input (PBP and A8) and those that do not (A9 ventral tier) (eg, Figure 7, top: a to a', b to b', $\mathrm{f}$ to $\mathrm{f}$, pink asterisks).

\section{DISCUSSION}

While CeN and BSTL inputs to the midbrain DA system are long known (Dong and Swanson, 2004; Fudge and Haber, 2000, 2001; Georges and Aston-Jones, 2001; Gonzales and Chesselet, 1990; Krettek and Price, 1978; Lee et al, 2005; Wallace et al, 1992; Zahm et al, 2011; Zahm et al, 1999), the organization of inputs from the entire CEA to specific DA neuronal subpopulations in nonhuman primates has not been mapped. Our data show that the entire CeM-SLEAcBSTLP trajectory has a direct input to the PBP and RRF regions of the ventral midbrain, with relatively less input to the medial VTA subnuclei. There was also modest input to the dorsal ventral tier (A9). Dual injections in the same animal indicated a tight spatial overlap between anterogradely labeled fibers issuing from the amygdala, and retrogradely labeled cells resulting from injections encompassing the PBP and A8 neuron groups along the entire CeM-SLEAcBSTLP corridor. The majority of CEA neurons that sent 

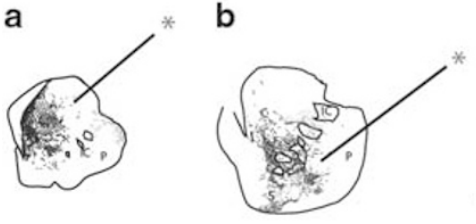

C

d

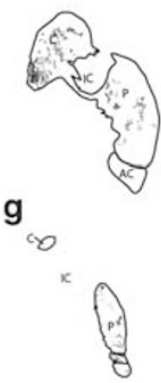

e

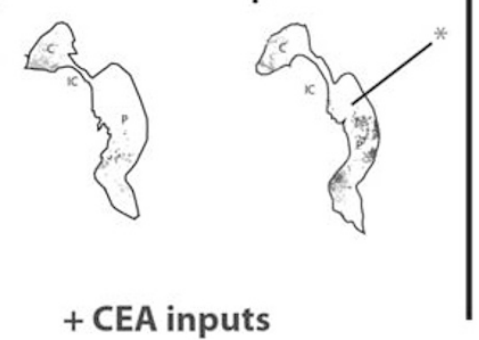

f

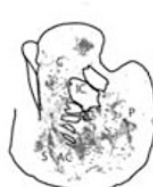

d'

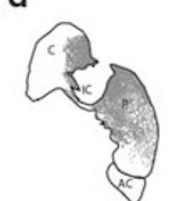

$g_{c o}^{\prime}$
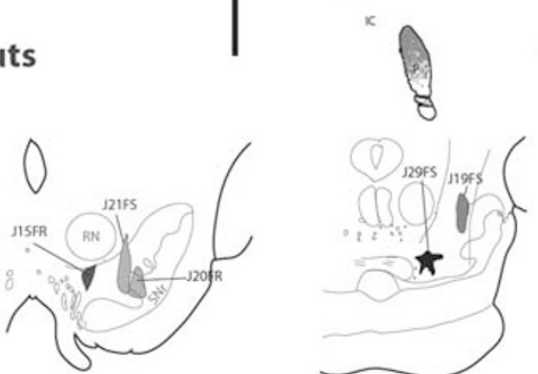

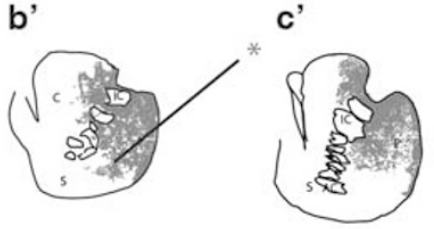

e'

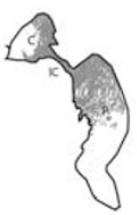

f'

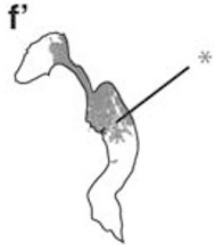

- CEA inputs

Figure 7 Collective view of the distribution of anterogradely labeled fibers in the striatum after injections that targeted the PBP and/or A8 subpopulations, and resulted in retrogradely labeled cells in the CEA $(\mathrm{a}-\mathrm{g})$. An injection into the A9 ventral tier that had few labeled cells in the CEA resulted in many anterogradely labeled fibers in the dorsal striatum ( $\left.a^{\prime}-g^{\prime}\right)$. Pink asterisks in $a, a^{\prime}, b, b^{\prime}$ and $f, f$ show examples where anterogradely labeled fibers from the $A 9$ ventral tier injection (blue) form patches that are dorsolaterally adjacent to labeled fibers originating from all PBP/A8 injection sites. This relationship is seen through the entire rostrocaudal extent of the striatum, ie, there is little overlap between the PBP/A8 projections and the A9 ventral tier projection. A full color version of this figure is available at the Neuropsychopharmacology journal online.

projections to these neuronal populations contained CRF. The PBP and A8 neuronal groups that receive CRF-enriched CEA inputs focus their efferent projections onto the rostral, central striatum, and the caudal ventromedial striatum. Previous work shows that these striatal regions receive inputs from dorsal anterior cingulate, orbitofrontal cortex and dorsolateral prefrontal cortex, creating a limbic-association interface (see below). In sum, the amygdala communicates with PBP, A8 and dorsal A9 subpopulations through a CRFenriched CEA pathway, to in turn modulate striatal regions linked to limbic-associative responses.

\section{CEA is a Continuous Interface Between Amygdala and DA System}

A key finding of these studies is that projections to the CEA (from the amygdala) and from the CEA (to the DA neuronal groups) were subdivision-specific (ie, based on the intrinsic organization of the CEA) rather than following a rostral (BSTL)-caudal (CeN) topography. Prior studies of individual pathways from the BSTL and CeN in mice (Kim et al, 2013), rats eg, (Dong et al, 2001; Jolkkonen et al, 2001; Krettek and Price, 1978) and monkey (Decampo and Fudge, 2013; Fudge and Tucker, 2009; Price and Amaral, 1981) detail specifics of amygdala and BSTL or CeN connectivity. Here, we used combinations of anterograde and retrograde injections to assess input/outputs from the entire CEA macrostructure across and within individual animals. The entire CeMSLEAc-BSTLP receives information from the basal/accessory basal nucleus and amygdalohippocampal area; labeled fibers conveying these inputs overlap CEA cells that project to the PBP and A8, and dorsal A9 subpopulations. In parallel, the CeLcn and BSTLen together received strong, albeit restricted, innervation from the ventromedial basal nucleus/CTA (analog of the rodent amygdalopiriform area) but few other amygdala nuclei, and had relatively less direct afferentation of ventral midbrain DA system. Amygdala efferents did not favor the BSTL or CeN, nor was there a differential output from the BSTL and CeN. Instead, histochemically symmetrical components of the CEA are innervated by the amygdala, and send efferents to the ventral midbrain, in an 'all or nothing' manner.

The concept of the CEA as a continuous macrostructure (Alheid and Heimer, 1988; Johnston, 1923), is based in part on neurochemical 'symmetry' of its subdivisions at the two poles of the BSTL and CeN (Alheid et al, 1995). The implication is that symmetrical subdivisions provide clues as to the connectional and functional organization of the macrostructure. The fact that amygdala-CEA-DA projections are organized through histochemically similar subdivisions, lends support to the concept of the 'extended amygdala'. This organization is important for understanding amygdala afferent control of the midbrain DA system.

\section{CEA Inputs Define a DA Path to the 'Limbic-Associative' Striatum in Monkeys}

Previous studies in monkeys show that DA cells well outside of the classic (midline) VTA send input to the 'limbic' structures of the ventral striatum (Haber et al, 2000) and 
amygdala (Cho and Fudge, 2010). Here, we found a sharp decline in inputs from the BSTL and CeN at the lateral boundary of the classic VTA, with most labeled axons terminating among the PBP neurons and A8 neurons, with some encroachment on the dorsal A9 region. The location of the PBP, A8, and dorsal A9 neurons fits those of the 'salience-detecting' neurons in the primate (Matsumoto and Hikosaka, 2009; Matsumoto and Takada, 2013). In turn, we found that these subregions (presumptive 'salience' neurons) project to striatal zones that also receive converging inputs from the orbitofrontal cortex, dorsal anterior cingulate, and dorsolateral prefrontal circuits (for review (Haber, 2014)). We refer to this striatal region as 'limbic-associative striatum' due to highly interleaved projections from cortical regions that play roles in flexibly altering cognitive strategies when options or potential opportunities change (O'Doherty, 2004; Rushworth et al, 2011). In contrast, the ventromedial striatum (which receives relatively more inputs from the ventromedial cingulate (eg, area 25) (Haber et al, 2006)) and the dorsolateral striatum (which receives input from premotor and motor cortices (Calzavara et al, 2007)), are relatively excluded from the CEA-DA-striatal circuit.

The CEA projections to the DA system are critical for 'surprise-enhancement' of associative learning in rats (reviewed in (Holland and Schiffino, 2016; McNally et al, 2011)). Surprise-enhanced learning occurs when conditioning cues are paired with unconditioned cues in an unpredicted fashion. This results in faster associative learning compared with when cues are predictably presented together (Esber and Haselgrove, 2011). In contrast to predicted pairings, which reinforce approach behavior, unpredicted cue pairings increase attention and learning. These dissociations raise the possibility that approach and associative learning functions may be sub-served by different DA subcircuits.

Here, we present anatomic data in primates that show that the CEA is wired to be a direct route by which information about unpredicted, salient events can alter DA activity, with downstream modulatory effects on striatal regions involved in planning and decision-making. DA activity in this specific path may enhance learning and coping strategies in the face of unpredicted events, as opposed to 'approach' behaviors in the ventromedial striatum. Unpredicted events challenge the animal to redirect its energies, and are therefore broadly defined as 'stressors' (Koolhaas et al, 2011). Defined in this way, stressors can energize new strategies to promote adaptation, or-depending on duration and controllability-can become overwhelming and deleterious. The ability to cope effectively and flexibly with new information may depend on CEA inputs to decision-making and planning circuits via specific DA subpopulations. Interestingly, we found that these CEA-DA circuits co-contain CRF peptide, suggesting a role for this 'stress' neuromodulator in shaping these responses.

\section{Challenges for Translational Studies}

DA neuronal function is more heterogeneous than previously thought, and the physiologic properties of individual DA cells may be circuit-dependent, based on mouse models (Beier et al, 2015; Lammel et al, 2012; Lerner et al, 2015; Zhang et al, 2015). Despite rapidly emerging evidence that specific circuits drive differential DA responses and behaviors, direct translation to the nonhuman primate is difficult. Across species, there are positional shifts in the main DA subpopulations, relative expansion of some DA subpopulations (ie, the PBP and A8 group), and large differences in the proportion of dopaminergic to non-dopaminergic cells in the various neuronal subpopulations (Francois et al, 1999; Halliday and Tork, 1986; Hirsch et al, 1992; Li et al, 2013; Nair-Roberts et al, 2008; Sanchez-Catalan et al, 2014; Taylor et al, 2014). A critical translational need is to identify the molecular and physiological phenotypes of midbrain DA neurons in monkeys and humans, and their specific input/ outputs, in order to understand DA circuit function in humans.

As noted, in monkeys, midbrain DA neurons code reward prediction errors to enable reinforcement learning (Schultz et al, 1993), but some DA neurons also emit signals related to salience of non-rewarding stimuli, including aversive events (Matsumoto and Hikosaka, 2009; Matsumoto and Takada, 2013). Value-coding neurons have been localized to the VTA and ventromedial SNc, and salience encoding neurons found in the ventromedial and dorsolateral SNc, including the RRF. In human neuroimaging studies, 'VTA/ ventromedial SNc' activations correlate with appetitive learning, whereas 'dorsolateral SNc/RRF' activity is most correlated with cues that predict aversive outcomes (Pauli et al, 2015). These functional general dissociations, however, have yet to be correlated with specific DA subpopulations and their circuits in higher species.

Although we found that CRF was highly expressed in the CEA-DA path, consistent with the situation in rodents (Cassell and Gray, 1989; Gray, 1993), the extent to which it co-localizes in GABAergic vs glutamatergic neurons in these projections is an open question. In rat VTA, CRF-positive terminals are found on both dopaminergic and nondopaminergic neurons, and 90\% of CRF-positive synapses on DA cells are asymmetric (excitatory) (Tagliaferro and Morales, 2008). As a 'neuroregulator', CRF exerts effects by altering intracellular signaling to facilitate or inhibit the effects of co-released primary transmitters or neuromodulators (Orozco-Cabal et al, 2006). Like many neuropeptides, CRF facilitates release of calcium from intracellular stores (Petersen et al, 1994), and may thus enable fine-tuning of DA spiking across relatively long time periods (Orozco-Cabal et al, 2006; Riegel and Williams, 2008). To understand how CRF mechanistically alters post-synaptic responses through the CEA inputs, it will be critical to understand how it is co-localized with primary transmitters.

Equally important will be understanding basic questions such as the diversity of cell types that receive and send projections through this circuit. There is renewed interest in exploring DA neuron diversity in primate studies in order to achieve insights into primate-specific behaviors that are influenced by the DA system (Root et al, 2016). For the specifics of the CEA-DA-striatal path, many questions exist. What is the ratio of dopaminergic to non-dopaminergic cells across the $\mathrm{PBP}$ and $\mathrm{A} 8$, and what are their neurochemical profiles? Which cell types are the main post-synaptic partners of CEA axons, and does this differ by subregion? Do CRF-containing terminals indeed contact DA cells that project to the striatum? The answer to these and other questions must be answered at the synaptic level. Although 
getting answers will require extensive sampling given the size of the primate brain, we now have the circuit map to move forward with these important questions.

\section{FUNDING AND DISCLOSURE}

The authors declare no conflict of interest.

\section{ACKNOWLEDGMENTS}

We appreciate assistance with extensive histologic work from Nanette Alcock. This work was supported by the National Institute of Mental Health, R01MH-63291-16 (JLF) and The Xerox Corporation program for undergraduate scholars (LP).

\section{AUTHOR CONTRIBUTIONS}

JLF designed the research. JLF, EAK, RP, JLB, LP, and BH analyzed the data. JLF and EAK wrote the paper.

\section{REFERENCES}

Alheid GF, DeOlmos CA, Beltramino CA. Amygdala and extended amygdala. In: Paxinos G (ed). The Rat Nervous System. 2nd edn, Academic Press: San Diego, 1995, pp 495-578.

Alheid GF, Heimer L (1988). New perspectives in basal forebrain organization of special relevance for neuropsychiatric disorders: the striatopallidal, amygdaloid, and corticopetal components of substantia innominata. Neuroscience 27: 1-39.

Bassett JL, Foote SL (1992). Distribution of corticotropin-releasing factor-like immunoreactivity in squirrel monkey (Saimiri sciureus) amygdala. J Comp Neurol 323: 91-102.

Beier KT, Steinberg EE, DeLoach KE, Xie S, Miyamichi K, Schwarz L et al (2015). Circuit architecture of VTA dopamine neurons revealed by systematic input-output mapping. Cell 162: 622-634.

Brischoux F, Chakraborty S, Brierley DI, Ungless MA (2009). Phasic excitation of dopamine neurons in ventral VTA by noxious stimuli. Proc Natl Acad Sci USA 106: 4894-4899.

Bromberg-Martin ES, Matsumoto M, Hikosaka O (2010). Dopamine in motivational control: rewarding, aversive, and alerting. Neuron 68: 815-834.

Calzavara R, Mailly P, Haber SN (2007). Relationship between the corticostriatal terminals from areas 9 and 46, and those from area $8 \mathrm{~A}$, dorsal and rostral premotor cortex and area $24 \mathrm{c}$ : an anatomical substrate for cognition to action. Eur J Neurosci 26: 2005-2024.

Cassell MD, Gray TS (1989). Morphology of peptide-immunoreactive neurons in the rat central nucleus of the amygdala. J Comp Neurol 281: 320-333.

Cho YT, Ernst M, Fudge JL (2013). Cortico-amygdala-striatal circuits are organized as hierarchical subsystems through the primate amygdala. J Neurosci 33: 14017-14030.

Cho YT, Fudge JL (2010). Heterogeneous dopamine populations project to specific subregions of the primate amygdala. Neuroscience 165: 1501-1518.

Chung CY, Seo H, Sonntag KC, Brooks A, Lin L, Isacson O (2005). Cell type-specific gene expression of midbrain dopaminergic neurons reveals molecules involved in their vulnerability and protection. Hum Mol Genet 14: 1709-1725.

Cote P-Y, Sadikot AF, Parent A (1991). Complementary distribution of calbindin D-28k and parvalbumin in the basal forebrain and midbrain of the squirrel monkey. Eur J Neurosci 3: 1316-1329.

Cummings S, Elde R, Ells J, Lindall A (1983). Corticotropinreleasing factor immunoreactivity is widely distributed within the central nervous system of the rat: an immunohistochemical study. J Neurosci 3: 1355-1368.

De Olmos JS. Amygdala. In: Paxinos G(ed). The Human Nervous System. Academic Press: San Diego, 1990, pp 583-710.

Decampo DM, Fudge JL (2013). Amygdala projections to the lateral bed nucleus of the stria terminalis in the macaque: comparison with ventral striatal afferents. J Comp Neurol 521: 3191-3216.

Dong HW, Petrovich GD, Swanson LW (2001). Topography of projections from amygdala to bed nuclei of the stria terminalis. Brain Res Brain Res Rev 38: 192-246.

Dong HW, Swanson LW (2004). Organization of axonal projections from the anterolateral area of the bed nuclei of the stria terminalis. J Comp Neurol 468: 277-298.

Esber GR, Haselgrove M (2011). Reconciling the influence of predictiveness and uncertainty on stimulus salience: a model of attention in associative learning. Proc Biol Sci 278: 2553-2561.

Francois C, Yelnik J, Tande D, Agid Y, Hirsch EC (1999). Dopaminergic cell group A8 in the monkey: anatomical organization and projections to the striatum. J Comp Neurol 414: 334-347.

Fudge JL, Haber SN (2000). The central nucleus of the amygdala projection to dopamine subpopulations in primates. Neuroscience 97: 479-494.

Fudge JL, Haber SN (2001). Bed nucleus of the stria terminalis and extended amygdala inputs to dopamine subpopulations in primates. Neuroscience 104: 807-827.

Fudge JL, Tucker T (2009). Amygdala projections to central amygdaloid nucleus subdivisions and transition zones in the primate. Neuroscience 159: 819-841.

Gaspar P, Heizmann CW, Kaas JH (1993). Calbindin D-28 K in the dopaminergic mesocortical projection of a monkey (Aotus trivirgatus). Brain Res 603: 166-172.

Geneser-Jensen FA, Blackstad TW (1971). Distribution of acetyl cholinesterase in the hippocampal region of the guinea pig. $Z$ Zellforsch 114: 460-481.

Georges F, Aston-Jones G (2001). Potent regulation of midbrain dopamine neurons by the bed nucleus of the stria terminalis. J Neurosci 21: RC160.

Gonzales C, Chesselet M-F (1990). Amygdalonigral pathway: An anterograde study in the rat with phaseolus vulgaris leucoagglutinin. J Comp Neurol 297: 182-200.

Gray TS (1993). Amygdaloid CRF pathways. Role in autonomic, neuroendocrine, and behavioral responses to stress. Ann NY Acad Sci 697: 53-60.

Haber SN (2014). The place of dopamine in the cortico-basal ganglia circuit. Neuroscience 282C: 248-257.

Haber SN, Fudge JL (1997). The primate substantia nigra and VTA: integrative circuitry and function. Crit Rev Neurobiol 11: 323-342.

Haber SN, Fudge JL, McFarland N (2000). Striatonigrostriatal pathways in primates form an ascending spiral from the shell to the dorsolateral striatum. J Neurosci 20: 2369-2382.

Haber SN, Kim KS, Mailly P, Calzavara R (2006). Reward-related cortical inputs define a large striatal region in primates that interface with associative cortical connections, providing a substrate for incentive-based learning. J Neurosci 26: 8368-8376.

Haber SN, Ryoo H, Cox C, Lu W (1995). Subsets of midbrain dopaminergic neurons in monkeys are distinguished by different levels of mRNA for the dopamine transporter: Comparison with the mRNA for the D2 receptor, tyrosine hydroxylase and calbindin immunoreactivity. J Comp Neurol 362: 400-410.

Halliday GM, Tork I (1986). Comparative anatomy of the ventromedial mesencephalic tegmentum in the rat, cat, monkey and human. J Comp Neurol 252: 423-445.

Heimer L, De Olmos JS, Alheid GF, Person J, Sakamoto N, Shinoda $\mathrm{K}$ et al. The human basal forebrain. Part II. In: Bloom FE, Bjorkland A, Hokfelt T (eds). Handbook of Chemical Neuroanatomy. Elsevier: Amsterdam. Vol 15: The Primate Nervous System, Part III, 1999, pp 57-226. 
Hirsch EC, Mouatt A, Faucheux B, Bonnet A-M, Javoy-Agid F, Graybiel AM et al (1992). Dopamine, tremor, and parkinson's disease. Lancet 340: 126-120.

Holland PC, Schiffino FL (2016). Mini-review: Prediction errors, attention and associative learning. Neurobiol Learn Mem 131: 207-215.

Johnston JB (1923). Further contributions to the study of the evolution of the forebrain. J Comp Neuro 35: 337-481.

Jolkkonen E, Miettinen R, Pitkanen A (2001). Projections from the amygdalo-piriform transition area to the amygdaloid complex: a PHA-l study in rat. J Comp Neurol 432: 440-465.

Kim SY, Adhikari A, Lee SY, Marshel JH, Kim CK, Mallory CS et al (2013). Diverging neural pathways assemble a behavioural state from separable features in anxiety. Nature 496: 219-223.

Kobayashi S, Schultz W (2008). Influence of reward delays on responses of dopamine neurons. J Neurosci 28: 7837-7846.

Koob GF, Rocio M, Carrera A, Gold LH, Heyser CJ, Maldonado-Irizarry C et al (1998). Substance dependence as a compulsive behavior. J Psychopharmacol 12: 39-48.

Koolhaas JM, Bartolomucci A, Buwalda B, de Boer SF, Flugge G, Korte SM et al (2011). Stress revisited: a critical evaluation of the stress concept. Neurosci Biobehav Rev 35: 1291-1301.

Krettek JE, Price JL (1978). Amygdaloid projections to subcortical structures within the basal forebrain and brainstem in the rat and cat. J Comp Neurol 178: 225-254.

Krishnan V, Han MH, Graham DL, Berton O, Renthal W, Russo SJ et al (2007). Molecular adaptations underlying susceptibility and resistance to social defeat in brain reward regions. [see comment]. Cell 131: 391-404.

Lammel S, Ion DI, Roeper J, Malenka RC (2011). Projection-specific modulation of dopamine neuron synapses by aversive and rewarding stimuli. Neuron 70: 855-862.

Lammel S, Lim BK, Ran C, Huang KW, Betley MJ, Tye KM et al (2012). Input-specific control of reward and aversion in the ventral tegmental area. Nature 491: 212-217.

Lavoie B, Parent A (1991). Dopaminergic neurons expressing calbindin in normal and parkinsonian monkeys. Neuroreport 2(10): 601-604.

Lee HJ, Groshek F, Petrovich GD, Cantalini JP, Gallagher M, Holland PC (2005). Role of amygdalo-nigral circuitry in conditioning of a visual stimulus paired with food. J Neurosci 25: 3881-3888.

Lerner TN, Shilyansky C, Davidson TJ, Evans KE, Beier KT, Zalocusky KA et al (2015). Intact-brain analyses reveal distinct information carried by $\mathrm{SNc}$ dopamine subcircuits. Cell 162: 635-647.

Li X, Qi J, Yamaguchi T, Wang HL, Morales M (2013). Heterogeneous composition of dopamine neurons of the rat A10 region: molecular evidence for diverse signaling properties. Brain Struct Funct 218: 1159-1176.

Mantsch JR, Baker DA, Funk D, Le AD, Shaham Y (2016). Stressinduced reinstatement of drug seeking: 20 years of progress. Neuropsychopharmacology 41: 335-356.

Margolis EB, Mitchell JM, Ishikawa J, Hjelmstad GO, Fields HL (2008). Midbrain dopamine neurons: projection target determines action potential duration and dopamine $\mathrm{D}(2)$ receptor inhibition. J Neurosci 28: 8908-8913.

Martin LJ, Powers RE, Dellovade TL, Price DL (1991). The bed nucleus-amygdala continuum in human and monkey. I Comp Neurol 309: 445-485.

Matsumoto M, Hikosaka O (2009). Two types of dopamine neuron distinctly convey positive and negative motivational signals. Nature 459: 837-841.

Matsumoto M, Takada M (2013). Distinct representations of cognitive and motivational signals in midbrain dopamine neurons. Neuron 79: 1011-1024.

McDonald AJ (2003). Is there an amygdala and how far does it extend? An anatomical perspective. Ann NY Acad Sci 985: 1-21.
McDonald AJ, Shammah-Lagnado SJ, Shi C, Davis M (1999). Cortical afferents to the extended amygdala. Ann N Y Acad Sci 877: 309-338.

McNally GP, Johansen JP, Blair HT (2011). Placing prediction into the fear circuit. Trends Neurosci 34: 283-292.

McRitchie DA, Halliday GM (1995). Calbindin D28K-containing neurons are restricted to the medial substantia nigra in humans. Neuroscience 65: 87-91.

McRitchie DA, Hardman CD, Halliday GM (1996). Cytoarchitectural distribution of calcium binding proteins in midbrain dopaminergic regions of rats and humans. J Comp Neurol 364: $121-150$.

Nair-Roberts RG, Chatelain-Badie SD, Benson E, White-Cooper H, Bolam JP, Ungless MA (2008). Stereological estimates of dopaminergic, GABAergic and glutamatergic neurons in the ventral tegmental area, substantia nigra and retrorubral field in the rat. Neuroscience 152: 1024-1031.

O'Doherty JP (2004). Reward representations and reward-related learning in the human brain: insights from neuroimaging. Curr Opin Neurobiol 14: 769-776.

Oler JA, Tromp DP, Fox AS, Kovner R, Davidson RJ, Alexander AL et al (2016). Connectivity between the central nucleus of the amygdala and the bed nucleus of the stria terminalis in the nonhuman primate: neuronal tract tracing and developmental neuroimaging studies. Brain Struct Funct 222: 21-39.

Olszeskwi J, Baxter D. Cytoarchitecture of the Human Brainstem, 3rd, revised and extended edn. Karger: Basel, 2014.

Olszewski J, Baxter D. Cytoarchitecture of the Human Brain Stem S. Karger: Basil, 1954.

Orozco-Cabal L, Pollandt S, Liu J, Shinnick-Gallagher P, Gallagher JP (2006). Regulation of synaptic transmission by CRF receptors. Rev Neurosci 17: 279-307.

Pauli WM, Larsen T, Collette S, Tyszka JM, Seymour B, O'Doherty JP (2015). Distinct contributions of ventromedial and dorsolateral subregions of the human substantia nigra to appetitive and aversive learning. J Neurosci 35: 14220-14233.

Pearson J, Goldstein M, Markey K, Brandeis L (1983). Human brainstem catecholamine neuronal anatomy as indicated by immunocytochemistry with antibodies to tyrosine hydroxylase. Neuroscience 8: 3-32.

Petersen OH, Petersen CC, Kasai H (1994). Calcium and hormone action. Annu Rev Physiol 56: 297-319.

Pignatelli M, Bonci A (2015). Role of dopamine neurons in reward and aversion: a synaptic plasticity perspective. Neuron 86: 1145-1157.

Pitkanen A, Savander V, LeDoux JE (1997). Organization of intraamygdaloid circuitries in the rat: an emerging framework for understanding functions of the amygdala. Trends Neurosci 20: 517-523.

Price JL, Amaral DG (1981). An autoradiographic study of the projections of the central nucleus of the monkey amygdala. J Neurosci 1: 1242-1259.

Price JL, Russchen FT, Amaral DG. The limbic region. II. The amygdaloid complex. In: Hokfelt BT, Swanson LW (eds). Handbook of Chemical Neuroanatomy. Elsevier: Amsterdam, 1987, pp 279-381.

Radley J, Morilak D, Viau V, Campeau S (2015). Chronic stress and brain plasticity: Mechanisms underlying adaptive and maladaptive changes and implications for stress-related CNS disorders. Neurosci Biobehav Rev 58: 79-91.

Reyes S, Fu Y, Double K, Thompson L, Kirik D, Paxinos G et al (2012). GIRK2 expression in dopamine neurons of the substantia nigra and ventral tegmental area. J Comp Neurol 520: 2591-2607.

Riegel AC, Williams JT (2008). CRF facilitates calcium release from intracellular stores in midbrain dopamine neurons. Neuron 57: 559-570.

Root DH, Wang HL, Liu B, Barker DJ, Mod L, Szocsics P et al (2016). Glutamate neurons are intermixed with midbrain dopamine neurons in nonhuman primates and humans. Sci Rep 6: 30615. 
Rushworth MF, Noonan MP, Boorman ED, Walton ME, Behrens TE (2011). Frontal cortex and reward-guided learning and decision-making. Neuron 70: 1054-1069.

Sanchez-Catalan MJ, Kaufling J, Georges F, Veinante P, Barrot M (2014). The antero-posterior heterogeneity of the ventral tegmental area. Neuroscience 282C: 198-216.

Schein JC, Hunter DD, Roffler-Tarlov S (1998). Girk2 expression in the ventral midbrain, cerebellum, and olfactory bulb and its relationship to the murine mutation weaver. Dev Biol 204: 432-450.

Schultz W, Apicella P, Ljungberg T (1993). Responses of monkey dopamine neurons to reward and conditioned stimuli during successive steps of learning a delayed response task. J Neurosci 13: 900-913.

Shammah-Lagnado SJ, Santiago AC (1999). Projections of the amygdalopiriform transition area (APir). A PHA-L study in the rat. Ann NY Acad Sci 877: 655-660.

Tagliaferro P, Morales M (2008). Synapses between corticotropinreleasing factor-containing axon terminals and dopaminergic neurons in the ventral tegmental area are predominantly glutamatergic. J Comp Neurol 506: 616-626.

Taylor SR, Badurek S, Dileone RJ, Nashmi R, Minichiello L, Picciotto MR (2014). GABAergic and glutamatergic efferents of the mouse ventral tegmental area. J Comp Neurol 522: 3308-3334.

Ulrich-Lai YM, Herman JP (2009). Neural regulation of endocrine and autonomic stress responses. Nat Rev Neurosci 10: 397-409.

Volman SF, Lammel S, Margolis EB, Kim Y, Richard JM, Roitman MF et al (2013). New insights into the specificity and plasticity of reward and aversion encoding in the mesolimbic system. J Neurosci 33: 17569-17576.
Wallace DM, Magnuson DJ, Gray TS (1992). Organization of amygdaloid projections to brainstem dopaminergic, noradrenergic, and adrenergic cell groups in the rat. Brain Res Bull 28: 447-454.

Yamada T, McGeer PL, Baimbridge KG, McGeer EG (1990). Relative sparing in parkinson's disease of substantia nigra dopamine neurons containing calbindin-D28K. Brain Res 526: 303-307.

Zahm DS, Cheng AY, Lee TJ, Ghobadi CW, Schwartz ZM, Geisler S et al (2011). Inputs to the midbrain dopaminergic complex in the rat, with emphasis on extended amygdala-recipient sectors. J Comp Neurol 519: 3159-3188.

Zahm DS, Jensen SL, Williams ES, Martin JR 3rd (1999). Direct comparison of projections from the central amygdaloid region and nucleus accumbens shell. Eur J Neurosci 11: 1119-1126.

Zhang S, Qi J, Li X, Wang HL, Britt JP, Hoffman AF et al (2015). Dopaminergic and glutamatergic microdomains in a subset of rodent mesoaccumbens axons. Nat Neurosci 18: 386-392.

(c) (i) (-) $€$ This work is licensed under a Creative Commons Attribution-NonCommercial-NoDerivs

International License. The images or other third party material in this article are included in the article's Creative Commons license, unless indicated otherwise in the credit line; if the material is not included under the Creative Commons license, users will need to obtain permission from the license holder to reproduce the material. To view a copy of this license, visit http://creativecommons.org/licenses/by-nc-nd/4.0/

(C) The Author(s) 2017

Supplementary Information accompanies the paper on the Neuropsychopharmacology website (http://www.nature.com/npp) 